\title{
Trends in Industry 4.0 Research: A Bibliometric Analysis of Publications in Internet of Thing Component
}

\author{
Abba Adam, Norhayati B. Zakuan, Hamed Gholami, Ado Abdu Bichi, Salisu Alh. Uba
}

\begin{abstract}
This research was carried out to provide a comprehensive bibliometric analysis of published research on Internet of Thing (IoT) in order to appreciate the trends and compare the publications contributions among different countries, institutions, authors, subject areas and other knowledge domains. The publications on the IoT were retrieved from Scopus database covering a period of $2009-2018$. A total of 9,367 articles were identified after different search steps. The analyses were conducted using bibliometric procedure. The largest number of publications were recorded in 2018 (3,712). The results further revealed that, China contributed the highest proportion of $3018(32.2 \%)$ publications, the USA was ranked second with total publications of 1348 (14.4\%). The most productive journals of publications were IEEE Access and IEEE Internet of Things Journal with 465 publications each with total citation of 103,978. Similarly, the most productive authors were Yang, Laurence with 29 (h-Index 14), followed by Sangaiah, with 27 (h-Index) while Rodrigues is the least with 20 (h-Index). The top two authors has cumulative citations of 1,331. The bibliometric analysis of subject area revealed that, Computer Science with 2,987 (32\%) followed by Engineering with 2597 (27.7\%). However, among the top areas of research in IoT, business, management and accounting is ninth with a contribution of 188 (2\%) publications only from 2009 to 2018. Additionally, affiliations, keywords, language, funding agencies information were clearly reported. Finally, this study provide an important inside for researchers in all the field of learning and serve as motivation for engagement in research activities as well as collaborations among scientist for meaningful research output.
\end{abstract}

Keywords: Internet of Thing, industry 4.0, smart factory, smart office.

\section{INTRODUCTION}

The Internet of Things (IoT) is an emerging term that combines different technologies and approaches, based on the connection between physical things and the Internet [1]. According to [2]. IoT is the connection through the Internet of physical world objects, which are equipped with sensors, actuators and communication technologies. IoT can have

Revised Manuscript Received on October15, 2019.

Abba Adamu*, Department of Business Administration, Azaman Hashim International Business School, Universiti Teknologi, Malaysia, Johor 81310, Malaysia \&

Norhayati B. Zakuan, Department of Business Administration, Azaman Hashim International Business School, Universiti Teknologi, Malaysia, Johor 81310, Malaysia

Hamed Gholami, Department of Manufacturing \& Industrial Engineering, School of Mechnical Engineering, Faculty of Engineering Universiti Teknologi, Malaysia, Johor 81310, Malaysia

Ado Abdu Bichi, Faculty of Education, Yusuf Maitama Sule University, Kano, Nigeria.

Salisu Alh. Uba, FCIPS Department of Design, Manufacturing and Engineering Management University of Strathclyde, Glasgow G1 1XJ United Kingdom. multiple application domains, such as manufacturing, health, transport, and energy, facilitating the development of new applications and improving existing uses. The Internet of Thing (IoT) is a developing term, which combines different devices of technology and methods for connecting between the Internet and physical devices [3]. IoT is defined as an integrated connected system where devices communicate through a broad network such as the internet [4] [5] In a manufacturing environment, this enables production lines and machinery to communicate and share information in real-time, creating a more collaborative and effective system [4] Cloud systems or cloud computing enable firms to store big amounts of data that can be accessed from anywhere [6].

Digitalisation described as integrating new technologies into daily life by digitising all that can be digitized. Furthermore, in the era of industrial digitalisation, businesses progressively invest in instruments and for finding solutions, which enable their processes, machines, employees and even products to be incorporated into a single integrated information collection network, data analysis, business growth assessment and performance improvement [7] [8]. Industry 4.0 is a popular word to describe the trend towards digitalisation and automating of the production as well as people's environment in recent years [9]. In other words, Industry 4.0 can be described as the increasing digitalisation and automation of the production processes from the technical point of view, as well as the creation of a digital value chain, to enable the communication between products and their environment [8]

Industry 4.0 explicitly includes a radical change in the way in which products flows and function, it is defined generally, as a global transformation of the industries through the advent of digitalisation and the Internet; these changes consider revolutionary changes in the design and production processes, activities and services of productions systems. A smart factory is referred to as the use of new innovative digital technology developments, including ' advanced robotics and artificial intelligence, hi-tech sensors, cloud computing, the Internet of Things, data capture and analytics, digital manufacturing (including 3D printing), applications as a service and other great marketing models, mobile devices, platforms that use engine and transmission algorithms. Although coined in Germany, the concept of Industry 4.0 shares commonalities to a significant extent with innovations in other European nations where it has been labelled differently, e.g. 
Smart Factories, Smart Industry, Advanced Trade or Industrial Internet of Things [10].

Previous empirical studies as well as review investigated the application of industry 4.0 emphasizing on the Internet of Thing (IoT) from different perspectives such as in the field of engineering, science and technology as well as some areas in public health and environmental sciences [11]. Industry 4.0 can have a significant effect on the organizational operation, improving company's environmental operations as a major cooperates responsibility of every company [12]. Similarly, empirical studies have established that, integrating technological application into organizations' corporate operations improved business environment and economic performances [13].

Generally, studies examine the application of Internet of Thing in almost all field of sciences, engineering, life sciences, management and environmental sciences where the efficacy of IoT was highlighted in improving all areas of human endeavors. However, the detail review of studies on the application of IoT and current status in all areas of human endeavor, which are very important to understand its wide application feasibility and future research application area, are still unclear. This study therefore, aimed at providing a comprehensive review of the published IoT related researches in all field from 2009 to 2018 , to understand the trends and area that need improvement. A bibliometric procedure is employed to analyse the related studies. Bibliometric is the widely used method to map knowledge domain in all areas.

\section{A. Objective of the Study}

The main purpose of the present study is to conduct a bibliometric analysis of published researches on Internet of Thing research and specifically to meet the following objectives (a) Investigate the growth pattern and distribution of Internet of Thing research literature from 2009 to 2018 (b) Identify the features of core authors and journals that contain substantial proportion of Internet of Thing research and (c) Identify the key research domain including country, area of application, funding agencies, affiliation, language and keywords of Internet of Thing research domain

\section{METHODOLOGY}

This study employed the Bibliometric analysis procedure to address the objective of this study. The Bibliometric study is a popular quantitative technique for the analysis of published documents articles or studies (Abbott et al., 2018), therefore, bibliometric is the suitable methods to apply in order to quantify and visualize the research contribution in the area of industry 4.0 Internet of Thing research. In utilizing the method, the researchers employed statistical techniques to analysed the Internet of Thing research literature in terms of authors performances, the journals, research institutes and countries in order to discover the trends and future direction [14]. The analysis also takes into considerations, the citations, keywords and mapping of knowledge domain. In line with the objectives of this study and the preceding explanations, the study was carried out in the following steps; (i) Documents search and retrieval from Scopus database (ii) Bibliometric quantitative analyses of the 9,367 retrieved articles. The bibliometric quantitative analyses were conducted to investigate the trends of the publications within the selected
10 years (2009-2018), the subject areas of applications, authors productivity, journal productivity as well as citations with the Citescore and impact factor, keywords occurrences was also investigated with affiliation and funding. The detail study framework is presented in Figure 1.

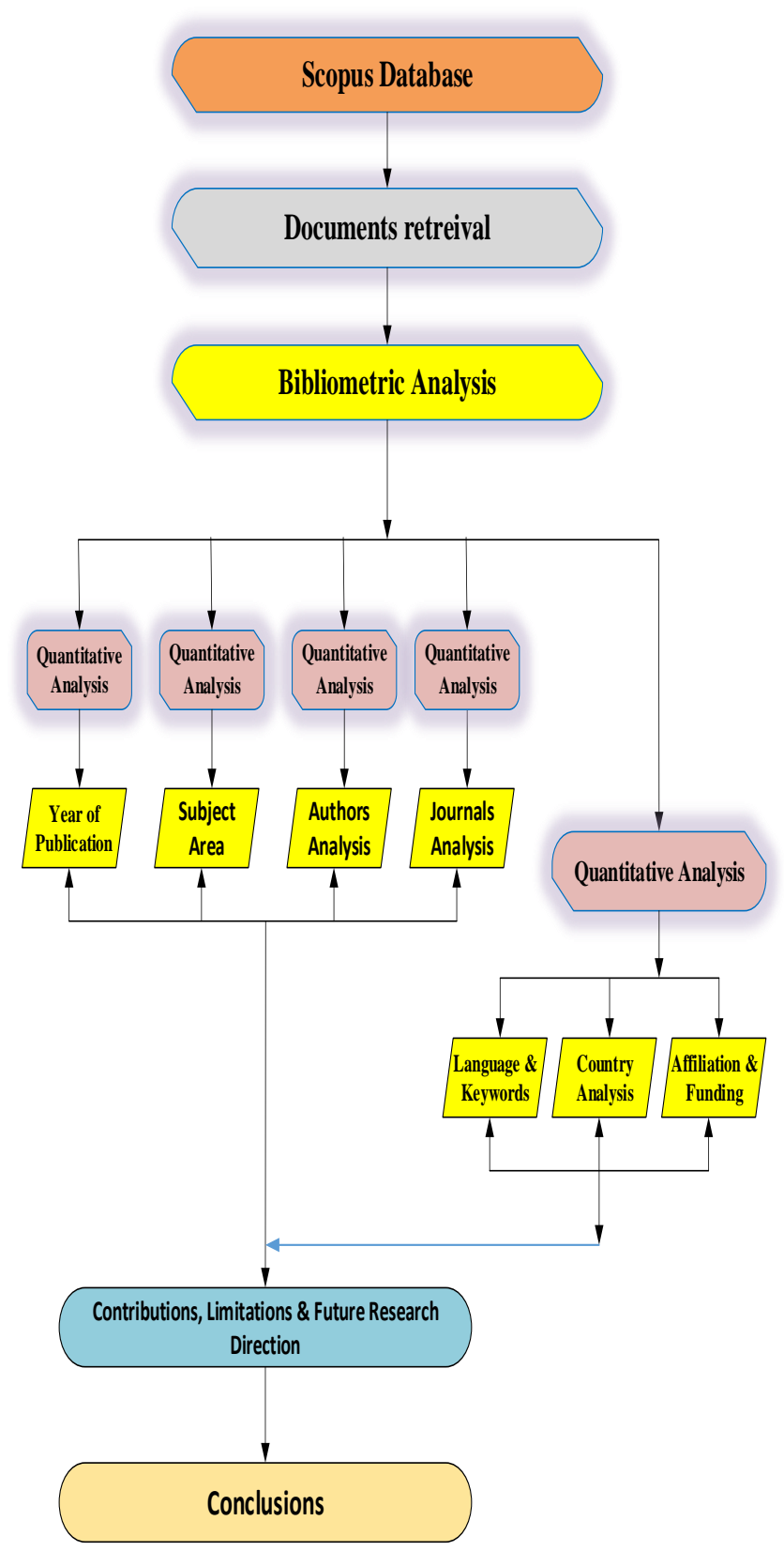

Figure 1: Research framework of the current study

\section{A. Data source and search strategy}

The data search and retrieval was conducted using Scopus database. The Scopus is a prestigious and influential scientific database; because it covers published researches with citations in the entire field. Thus it is the one of the valuable tool for bibliometric studies [15]. The Scopus was used because it provides more than $20 \%$ of the coverage of all scientific publications more than any other database including web of science [16]. Based on the above narrations, this study utilizes the Scopus database to retrieve all the literature used in this study.

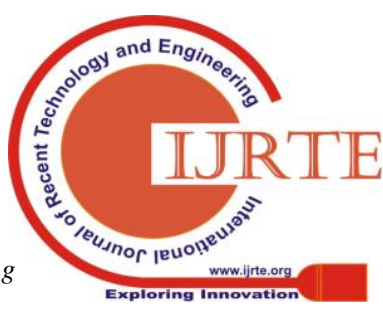


Data retrieval was done from August 30th to 5th September 2019 from the Scopus database. The researchers conducted searches with central theme or code to retrieve the articles relevant to the research objectives. The term used was any articles containing "cyber physical system* in the article's abstract, title or key. Based on the objective of this study, the oldest publications are considered to be published in 2009 and the more recent is 2018. The first query string used was (TITLE-ABS-KEY ("Internet of Thing *") and this produced 42,059 document results. After inspecting these articles, it was discovered that, some articles were published in 2019 and some for 2020 , in order to limit the articles to the 2009 to 2018 this query was used to limit the articles to the years under investigation thus; (TITLE-ABS-KEY ("Internet of Thing *") AND (EXCLUDE (PUBYEAR, 2020) OR EXCLUDE (PUBYEAR, 2019)). This second query resulted in retrieval of 10,045 documents.

Lastly to make sure that, no review article was included in the analysis, another query was used to excludes all the review articles after reading their details, all their EIDs were retrieved and added in the search query so that all the review should not appear in the results, the query further reads (TITLE-ABS ( " Internet of Thing *" ) ) AND NOT EID (insert EID of review articles here**) ) AND ( LIMIT-TO ( SRCTYPE, "j" ) ) AND ( LIMIT-TO ( DOCTYPE, "ar" )) AND ( EXCLUDE ( PUBYEAR, 2020 ) OR EXCLUDE ( PUBYEAR, 2019 ) ). This last query produced 9,367 researched based articles.

\section{B. Data Analysis}

In order to achieve the objectives of this study, the analysis of data generated from Scopus database in form of CSV format was used. Microsoft Excel 2016 was used to sort the data for the generation of tables, graphs and other statistical procedures. The top authors, journals, country, funding agencies etc. were ranked according to the publication rates and citations. The data visualization was conducted using the VOSviewer software to create networks based on countries, keywords and other information [17]. The VOSviewer has one unique advantage over other tools in mapping knowledge domain displays and is suitable for analyzing complex networks and large data with citations and keywords [17].

\section{RESULTS}

The data analysis was conducted as stated in the preceding section of data analysis. The results obtained from the analysis of the retrieved documents on Internet of Thing researches published from 2009 to 2018 are presented in line with objectives of the study. The findings have been presented and described under nine (9) headings as spelt out in the study purposes and frameworks thus: publications growth by year, subject area analysis, author productivity analysis, journal productivity analysis, language of writing analysis, keywords, country, affiliation, funding agencies analyses respectively.

\section{A. Publications Growth by Year of Publications}

The applied technique yielded 9,367 publications from 2009 to 2018 . The first article in this category was published in 2009 with two 17 publications; the annual publications were stable from 2009 up to 2010 . A dramatic increase was noticed from 2012 to 2018 . The number of articles during these years
(2012-2018) shows exponential growth in the trend. The annual documents and accumulated documents are shown in figure 2. The highest annual publications were seen in 2018 totaling 9,367. This representation provides a clear picture of the publication trend in IoT from 2009 to 2018

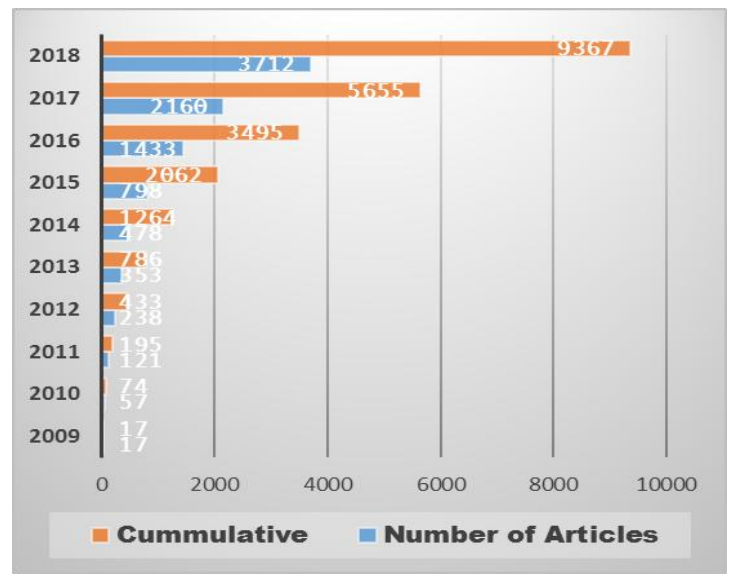

Figure 2: Publication growth by year

\section{B. Subject Area Analysis}

The bibliometric analysis of subject area where the research in IoT was presented on figure 3. Top 15 must productive fields of application were analysed. In line with the set standards for this review the total retrieved documents was 9,367 and among the retrieved articles 8810 (94.05\%) were published in 15 top subject areas selected in this study. The results presented on figure 3 shows that, out of the 8810 articles produced, computer Science has the highest number of publications with 2,987 (33.9\%), followed by Engineering field with a total of 2,597 $(29.5 \%)$. The third most popular filed was Physics and Astronomy with a total publication of $539(6.1 \%)$, material sciences were the fourth populous filed with total publications of 482 (5.5). Furthermore, looking into the pattern of publications in IoT as presented in figure 3 showed that business, management and accounting field is the ninth with $188(2.1 \%)$ and the last area with the application of IoT in the research with only $75(0.9 \%)$ publications produced from 2009 to 2018 was Medicine.

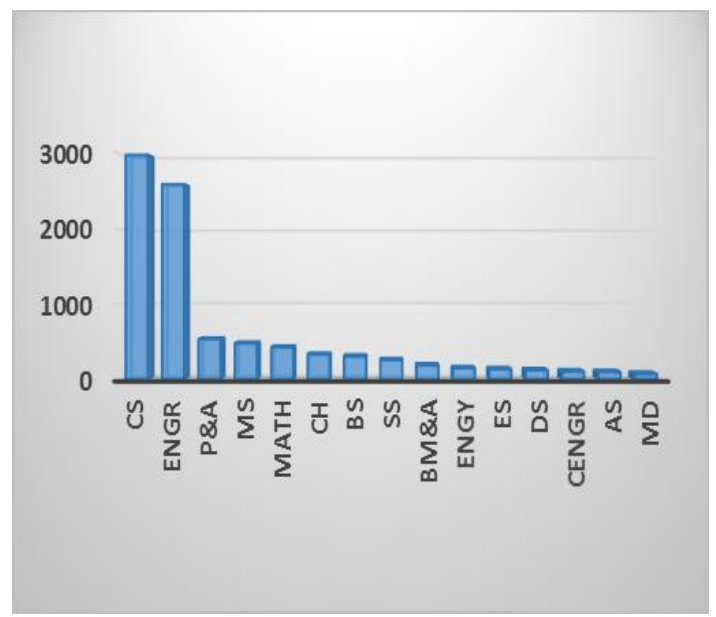

Figure 3: Distribution of documents by subject area

Published By:

Blue Eyes Intelligence Engineering DOI:10.35940/ijrte.C1238.1083S219 


\section{Trends in Industry 4.0 Research: A Bibliometric Analysis of Publications in Internet of Thing Component}

\section{C.Author Productivity Analysis}

The retrieved results show that, a total of 8,924 authors contributed to the publications of all the 2486 articles included in this study. Among the top 10 authors presented here The retrieved results show that, a total of 18,451 authors contributed to the publications of all the 9,367 articles included in this study. Among the top 15 authors presented here Yang, Laurence T. has the highest publications with 29, followed by Sangaiah, A., K. with 27 while Rodrigues is the least with 20 publications only. The details of most prolific authors as presented in Table 1 shows that, the top 15 authors selected for this study were cited for a total of 25,543. Atzori, L. was the most influential with a citation number of 8117 with h-index of 17 , followed by Lera, A. with citations of 7716 with h-index of 13 , details of citation and h-index can analyses were presented in Table 1 .

\section{Journal Productivity Analysis}

The 9,367 articles that meet the selection criteria and retrieved for this research were all published in 160 different relevant journals. The top 15 selected journals are the active journals in terms of IR 4.0 IoT components, the journals were presented in Table 2 . The total number of articles published in this field by the top 15 journals are 2601 representing $27.8 \%$ of the total retrieved items. The journals most prolific in the field of IoT were IEEE Access and IEEE Internet of Things Journalwith 465 publications each, followed by Sensors Switzerland with 434 publications. The citation analysis of the top 15 journals included in this section has a total citation of 103,978 . Further analysis shows that, Sensors Switzerland has the highest citations of 25,391 (24.4\%) followed by IEEE Access with the citations of 19,331 (18.6\%) and IEEE Communications Magazine with citations of 12,467 (12\%). However, the least cited journal is International Journal of Engineering and Technology with a citation of 18 (0.02\%).

\section{E. Language of Writing Analysis}

The bibliometric analysis of retrieved articles in IoT in terms languages of publications in which the article was written showed that, the 9,367 retrieved articles were written in nine (9) different languages classified into three (3) based on their strength (English, Chinese and others). The results show that, 8,711 (93\%) of the articles were written in English Language, followed by Chinese with 562 (6\%) while 94 (1\%) were written in other Languages. This showed that, the primary Language used in writing these reviewed articles is English.

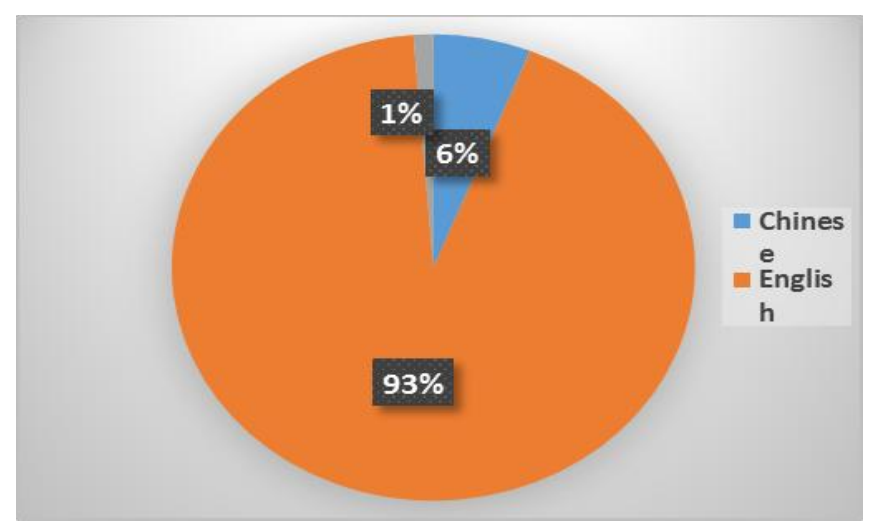

Figure 4: Language of Publications

\section{F. Keywords Analysis}

The keywords analysis resulted in identification of 19,635 total author keywords larger percentage of the keywords were used once. After re-labeling synonymic single words and congeneric phrases, 933 met the threshold of minimum five occurrences for the mapping in VOSviewer. After reviewing and removing the duplicates, 441 keywords were used for the analysis and mapping in VOSviewer. The results revealed that, Internet of Thing was the most frequently encountered keyword with 2,737 occurrences, this is followed by the industry 4.0 with 453 occurrences and the third most frequently occurred keyword was security with 358 occurrences. As presented in Figure 5 the larger circle size and font indicates higher occurrence.

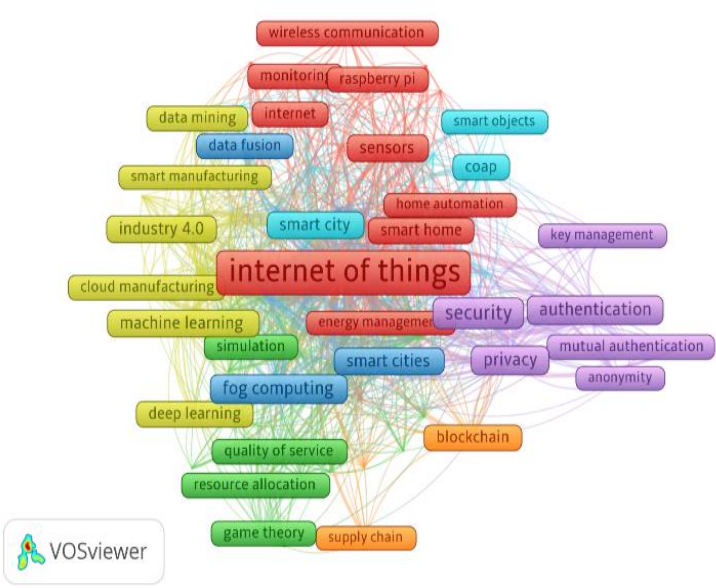

Figure 5: Keywords frequently encountered

\section{G. Country Analysis: Productivity and collaborations}

he distribution of the publications geographically involved 120 countries within the six continents (Figure 6). Among the 120 countries, 43 countries published less than five articles during this period (2009-2018). The analysis further shows that, 77 countries published at least five (5) articles each. The top 15 selected most productive countries as depicted in Fig. 6 showed that, China was ranked first with (3018 publications) followed by US with (1348 publications), South Korea (966 publications), India (850 publications), United Kingdom (632 publications), Italy (476 publications), Spain (423 publications), Taiwan (328 publications), Australia (292 publications), Canada (286 publications), Japan (278 publications), Germany (270 publications), France (266 publications), Saudi Arabia (181 publications) and Sweden (170 publications). These top 15 countries particularly have rapidly developed economies than their counter-part and their domestic research capacity and impact globally appears to have increased accordingly (Nafade et al., 2018) 
Table 1: Top 15 Leading Authors in IoT Research

\begin{tabular}{|c|c|c|c|c|c|c|c|c|}
\hline SN & Author & Scopus ID & $\begin{array}{l}\text { Year of } 1^{\text {st }} \\
\text { Publication }\end{array}$ & TP & h-index & $\mathrm{TC}$ & Current Affiliation & Country \\
\hline 1 & Yang, Laurence T. & 7406280812 & 2014 & 29 & 14 & 940 & Saint Francis Xavier University, Antigonish & Canada \\
\hline 2 & Sangaiah, A., K. & 55616335800 & 2015 & 27 & 11 & 391 & Vellore Institute of Technology, Vellore, Vellore, & India \\
\hline 3 & $\mathrm{Xu}, \mathrm{Lida}$ & 13408889400 & 2011 & 27 & 24 & 361 & $\begin{array}{l}\text { Old Dominion University, Department of Information Technology } \\
\text { and Decision Sciences, Norfolk, }\end{array}$ & United States \\
\hline 4 & Park, Jonghyuk & 55665406600 & 2013 & 26 & 8 & 266 & $\begin{array}{l}\text { Seoul National University of Science and Technology (SNUST), } \\
\text { Department of Computer Science and Engineering, Seoul, }\end{array}$ & South Korea \\
\hline 5 & Song, Houbing & 57199094588 & 2015 & 26 & 14 & 878 & $\begin{array}{l}\text { Embry-Riddle Aeronautical University, Department of Electrical } \\
\text { Engineering, Daytona Beach }\end{array}$ & United States \\
\hline 6 & Zeadally, Sherali & 7003472739 & 2011 & 26 & 14 & 815 & $\begin{array}{l}\text { University of Kentucky, College of Communication and } \\
\text { Information, Lexington }\end{array}$ & United States \\
\hline 7 & Choo, K. K. R. & 57208540261 & 2016 & 25 & 14 & 510 & $\begin{array}{l}\text { University of Texas at San Antonio, Department of Information } \\
\text { Systems and Cyber Security, San Antonio, }\end{array}$ & United States \\
\hline 8 & Qiu, Tie & 3497188200 & 2012 & 23 & 15 & 557 & Tianjin Key Laboratory of Advanced Networking, Tianjin, China & China \\
\hline 9 & Jara, Antonio J. & 35113243800 & 2011 & 22 & 13 & 967 & $\begin{array}{l}\text { HOP Ubiquitous, Murcia, SpainHaute Ecole Spécialisée de Suisse } \\
\text { Occidentale, Institute of Information Systems, Delemont, }\end{array}$ & Switzerland \\
\hline 10 & Atzori, Luigi & 57208011473 & 2010 & 21 & 17 & 8117 & Università degli Studi di Cagliari, UdR CNIT of Cagliari, Cagliari, & Italy \\
\hline 11 & Guizani, M. & 7004750176 & 2015 & 21 & 11 & 2416 & Qatar University, Doha & Qatar \\
\hline 12 & Lera, A. & 7007176996 & 2010 & 20 & 13 & 7716 & Universita degli Studi di Reggio Calabaria, Reggio Italy & Italy \\
\hline 13 & Liu, A. & 55925848400 & 2016 & 20 & 14 & 418 & Central South University, China, Changsha, China & China \\
\hline 14 & Ning, $\mathrm{H}$. & 9232973200 & 2011 & 20 & 11 & 590 & University of Science and Technology, Beijing & China \\
\hline 15 & Rodrigues, J.J.P.C & 25930566300 & 2010 & 20 & 13 & 601 & National Institute of Telecommunications (Intel) & Brazil \\
\hline
\end{tabular}


Trends in Industry 4.0 Research: A Bibliometric Analysis of Publications in Internet of Thing Component

Table 2: Top ten Leading Journals in IoT Research

\begin{tabular}{|c|c|c|c|c|c|c|c|}
\hline SN & Journal & $\begin{array}{l}\text { Number of } \\
\text { Publications }\end{array}$ & $\begin{array}{l}\text { Number of } \\
\text { Citations }\end{array}$ & $\begin{array}{l}\text { CiteScore } \\
2018\end{array}$ & Most Cited Article & Time cited & Publisher \\
\hline 1 & IEEE Access & 465 & 19,331 & 4.96 & $\begin{array}{l}\text { The internet of things for health care: A comprehensive survey } \\
\text { [18]. }\end{array}$ & 71 & IEEE \\
\hline 2 & IEEE Internet of Things Journal & 465 & 4,568 & 11.33 & Internet of things for smart cities [19] & 58 & IEEE \\
\hline 3 & Sensors (Switzerland) & 434 & 25,391 & 3.72 & $\begin{array}{l}\text { A study of Lora: Long range \& low power networks for the } \\
\text { internet of things[20] }\end{array}$ & 28 & $\begin{array}{l}\text { Multidisciplinary } \\
\text { Publishing Institute }\end{array}$ \\
\hline 4 & Future Generation Computer Systems & 191 & 4,447 & 6.30 & $\begin{array}{l}\text { Internet of Things (IoT): A vision, architectural elements, and } \\
\text { future directions[21] }\end{array}$ & 4086 & Elsevier \\
\hline 5 & $\begin{array}{l}\text { International Journal of Distributed } \\
\text { Sensor Networks }\end{array}$ & 189 & 2337 & 1.63 & Implementing Smart Factory of Industry 4.0: An Outlook[22] & 280 & SAGE \\
\hline 6 & IEEE Communications Magazine & 134 & 12467 & 11.27 & Mobile crowdsensing: Current state and future challenges [23] & 511 & IEEE \\
\hline 7 & $\begin{array}{l}\text { IEEE Transactions on Industrial } \\
\text { Informatics }\end{array}$ & 115 & 6,414 & 8.82 & $\begin{array}{l}\text { CCIoT-CMfg: Cloud computing and internet of things-based } \\
\text { cloud manufacturing service system[24] }\end{array}$ & 268 & IEEE \\
\hline 8 & $\begin{array}{l}\text { Wireless Communications and Mobile } \\
\text { Computing }\end{array}$ & 101 & 898 & 1.47 & $\begin{array}{l}\text { Semantic interoperability in heterogeneous IoT infrastructure for } \\
\text { healthcare[25] }\end{array}$ & 32 & Hindawi \\
\hline 9 & Wireless Personal Communications & 98 & 3477 & 1.28 & Software-Defined Fog Network Architecture for IoT[26] & 33 & Springer Nature \\
\hline 10 & IEEE Sensors Journal & 84 & 11,244 & 3.96 & $\begin{array}{l}\text { A distributed rss-based localization using a dynamic circle } \\
\text { expanding mechanism[27] }\end{array}$ & 334 & IEEE \\
\hline 11 & $\begin{array}{l}\text { Journal of Advanced Research in } \\
\text { Dynamical and Control Systems }\end{array}$ & 72 & 61 & 0.31 & $\begin{array}{l}\text { A novel method of supervision and control of first order level } \\
\text { process using Internet of Things [28] }\end{array}$ & 11 & $\begin{array}{l}\text { Institute of Advanced Scientific } \\
\text { Research }\end{array}$ \\
\hline 12 & Computer Networks & 71 & 9148 & 4.19 & The Internet of Things: A survey [29] & 6316 & Elsevier \\
\hline 13 & Ad Hoc Networks & 64 & 2048 & 4.52 & SVELTE: Real-time intrusion detection in the Internet of Things & 214 & Elsevier \\
\hline 14 & $\begin{array}{l}\text { Journal of Network and Computer } \\
\text { Applications }\end{array}$ & 62 & 2129 & 6.54 & A survey on trust management for Internet of Things[30] & 438 & Elsevier \\
\hline 15 & $\begin{array}{l}\text { International Journal of Engineering and } \\
\text { Technology }\end{array}$ & 56 & 18 & 0.08 & $\begin{array}{l}\text { Design and development of smart energy meter for effective use } \\
\text { of electricity in IoT applications[31]. }\end{array}$ & 5 & $\begin{array}{l}\text { Science Publishing Corporation } \\
\text { Inc. }\end{array}$ \\
\hline
\end{tabular}




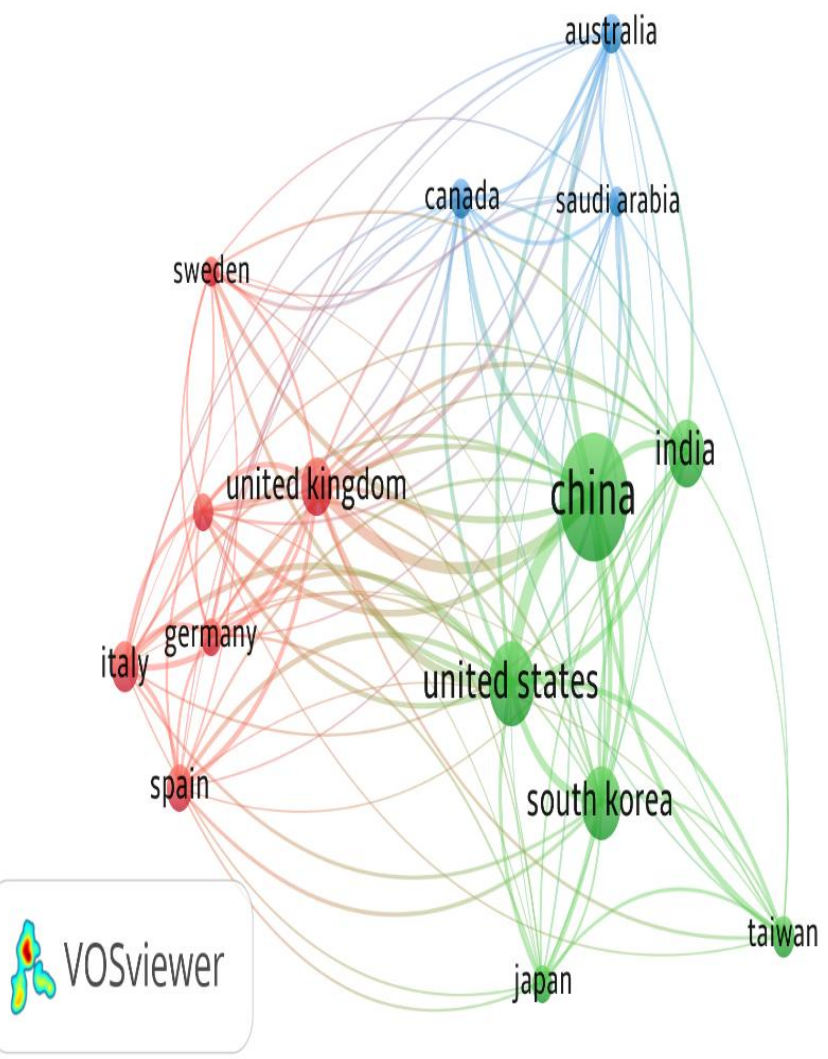

Figure 6: Top 15 Countries

Further information presented on Table 3 disclosed the total citations per country, link strength and cumulative citations by continents. As shown (Table 3), China lead with 36,873 citations followed by US with 32218 citations. The least most cited country was Japan with 2889 citations. Similarly, the distributions based on the strength of the country's collaboration link, shows that, China lead with 1270 link closely followed US with 1006 link. However, Taiwan was the least country in terms of strength link among top 15 productive countries with 141 reported in this study. The top most productive countries were from four continents among the 7 in the world, information from (Table 3) revealed that, Asia top the list with 5651 publications, followed by Europe with 2238, North America with 1634 while Australia was the least with only 292 publications. Concerning cumulative citations by continents China was the highest with 60,772 cumulative citations, followed closely by Europe with 56,833, North America was cumulative citations of 37,838, Australia was the last with 11,096 cumulative citations (Table 3).

\section{H. Affiliation Related Analysis}

The bibliometric analysis based on authors' affiliation were shared among the 120 countries with authors that published the 9,367 articles during this period (2009-2018). The analysis further showed that, the top 15 selected most productive affiliations presented in Table 4 showed that, Chinese Academy of Sciences was ranked first with (229 publications) followed by Beijing University of Posts and
Telecommunications with (192 publications), Ministry of Education China (169 publications), Vellore Institute of Technology (110 publications), Tsinghua University (105 publications), King Saud University (95 publications), Nanjing University of Post and Telecommunications (94 publications), Shanghai Jiao Tong University (88 publications) followed by others. However, Electronics and Telecommunications Research Institute, South Korea with 66 publications was the least institutions in terms of publications among the top 15 selected affiliations in this study. Overall, these results revealed that, Chinese Academy of Sciences has the highest number publications from 2009 to 2018.

\section{Funding Agencies Analysis}

The results on the funding agency analysis revealed that, out of the 15 top funding agencies, National Natural Science Foundation of China was the highest funding agency with a total of 1180 (12.6\%) funded publications; National Research Foundation of Korea followed this with 336 (3.59\%) publications funded from 2009 to 2018. The distribution further showed that, Ministry of Science, ICT and Future Planning South Korea was the third funding agency with funded $290(3.10 \%)$ publications, followed closely by Fundamental Research Funds for the Central Universities of China with 201 (2.15\%), National Science Foundation of United States with 189 (2.02\%) publications. However, as presented in the Table 4, the last among the top 15 funding agencies is Natural Science Foundation of Jiangsu Province, China with 47 publications.

\section{CONTRIBUTIONS OF THE STUDY}

Through the bibliometric analysis the finding of this review, provide a comprehensive representation of the application of Internet of Thing (Industry 4.0 component) in a multidisciplinary research area. The findings complement the industry 4.0 highly exposed influence in all areas of undertakings within the research community and lay a concrete base for future research in multi-disciplinary areas. Specifically, the discovery and identification of IoT based research in interdisciplinary areas provide a rigorous ground and motivation for researchers from different areas to engage in interdisciplinary and multidisciplinary collaborations for successful research results. The quantitative analysis of top sources journals is a guide to scholars in selecting target journals for examination of literature and submission of relevant manuscripts for possible publications in IoT related researches. The identification of top 15 documents/researches can facilitate research in IoT globally. Moreover, the analyses were based on systematic procedure and revealed potential gaps and direction for future study especially concerning area of application where more researches are needed to complement the other aspect of IoT applications. 
Trends in Industry 4.0 Research: A Bibliometric Analysis of Publications in Internet of Thing Component

Table 3: Top Country by Continents, Citations and Link Strength

\begin{tabular}{|c|c|c|c|c|c|c|}
\hline SN & Continent & Country & $\mathrm{TP}$ & Citations & Link Strength & Cumulative Citations \\
\hline \multirow[t]{6}{*}{1} & Asia & China & 3018 & 36873 & 1270 & $60,772.00$ \\
\hline & & South Korea & 996 & 8301 & 334 & \\
\hline & & India & 850 & 5958 & 235 & \\
\hline & & Taiwan & 328 & 3784 & 141 & \\
\hline & & Japan & 278 & 2889 & 154 & \\
\hline & & Saudi Arabia & 181 & 2967 & 177 & \\
\hline 2 & Australia & Australia & 292 & 11096 & 291 & $11,096.00$ \\
\hline \multirow[t]{6}{*}{3} & Europe & United Kingdom & 632 & 12507 & 523 & $56,833.00$ \\
\hline & & Italy & 476 & 19108 & 215 & \\
\hline & & Spain & 423 & 9827 & 192 & \\
\hline & & Germany & 270 & 5910 & 162 & \\
\hline & & France & 267 & 4507 & 207 & \\
\hline & & Sweden & 170 & 4974 & 162 & \\
\hline \multirow[t]{2}{*}{4} & North America & United States & 1348 & 32218 & 1006 & $37,838.00$ \\
\hline & & Canada & 286 & 5620 & 274 & \\
\hline
\end{tabular}

Table 4: Top 15 Affiliations

\begin{tabular}{|c|c|c|c|c|}
\hline $\mathrm{SN}$ & Institutions & Country & Documents & $\%$ \\
\hline 1 & Chinese Academy of Sciences & China & 229 & 2.44 \\
\hline 2 & Beijing University of Posts and Telecommunications & China & 192 & 2.05 \\
\hline 3 & Ministry of Education China & China & 169 & 1.80 \\
\hline 4 & Vellore Institute of Technology & India & 110 & 1.17 \\
\hline 5 & Tsinghua University & China & 105 & 1.12 \\
\hline 6 & King Saud University & Saudi Arabia & 95 & 1.01 \\
\hline 7 & Nanjing University of Post and Telecommunications & China & 94 & 1.00 \\
\hline 8 & Shanghai Jiao Tong University & China & 88 & 0.94 \\
\hline 9 & Xidian University & China & 84 & 0.90 \\
\hline 10 & University of Electronic Science and Technology, China & China & 76 & 0.81 \\
\hline 11 & Huazhong University of Science and Technology & China & 75 & 0.80 \\
\hline 12 & Beihang University & China & 73 & 0.78 \\
\hline 13 & Beijing Jiaotong University & China & 69 & 0.74 \\
\hline 14 & Wuhan University & China & 69 & 0.74 \\
\hline \multirow[t]{2}{*}{15} & Electronics and Telecommunications Research Institute & South Korea & 66 & 0.70 \\
\hline & Total & & 1594 & 17.02 \\
\hline
\end{tabular}

Table 4: Top 15 funding agency

\begin{tabular}{|c|c|c|c|c|}
\hline $\mathrm{SN}$ & Funding Agency & Country & Articles & $\%$ \\
\hline 1 & National Natural Science Foundation of China & China & 1180 & 12.60 \\
\hline 2 & National Research Foundation of Korea & South Korea & 336 & 3.59 \\
\hline 3 & Ministry of Science, ICT and Future Planning & South Korea & 290 & 3.10 \\
\hline 4 & Fundamental Research Funds for the Central Universities & China & 201 & 2.15 \\
\hline 5 & National Science Foundation & United State & 189 & 2.02 \\
\hline 6 & Ministry of Education, China & China & 151 & 1.61 \\
\hline 7 & National Basic Research Program of China & China & 143 & 1.53 \\
\hline 8 & Ministry of Science and Technology, Taiwan & Taiwan & 94 & 1.00 \\
\hline 9 & European Commission & Belgium & 93 & 0.99 \\
\hline 10 & Institute for Information \& Communications Technology Promotion & South Korea & 81 & 0.86 \\
\hline 11 & Engineering and Physical Sciences Research Council & China & 79 & 0.84 \\
\hline 12 & China Postdoctoral Science Foundation & China & 67 & 0.72 \\
\hline 13 & Natural Sciences and Engineering Research Council of Canada & Canada & 62 & 0.66 \\
\hline 14 & Japan Society for the Promotion of Science & Japan & 51 & 0.54 \\
\hline \multirow[t]{2}{*}{15} & Natural Science Foundation of Jiangsu Province & China & 47 & 0.50 \\
\hline & Total & & 3064 & 32.71 \\
\hline
\end{tabular}




\section{LIMITATIONS}

This study attempted to give a comprehensive bibliometric analyses of the published researches related to IoT in all areas of scientific researches, although significant effort has been put to ensure a robust bibliometric analysis was conducted, some few short comings that should be a concern for the researchers in future studies emerged. First, the published articles used in this study were collected from Scopus database alone which may not cover many other related research vital to the successful attainment of the objective of this study and that, the organization related information of the papers used may not be consistent since organizations names do not have consistent format. Thus, this study did not analyse the collaborative networks among different authors and institutions. Secondly, the study-identified literature on the IoT using "Internet of Thing" through the subject classification system of Scopus few articles may have been missed. Thirdly, IoT involve other sub-constructs or sub-systems (Digitalization, Smart Supply and Smart office) and due to insufficient integration of authors, their academic levels and in-depth analysis of different sub-systems and knowledge points was not performed.

\section{FUTURE RESEARCH DIRECTIONS}

In line for to the time and resources restraints on the part of the researchers' other areas that should have been considered were unavoidably ignored, further studies should consider using two different database or more to obtained a relatively larger documents that will allow comparison and conducting more comprehensive bibliometric analysis of the sourced data. In the same being and due to the dearth of IoT researches in the area of business management and accounting, researchers especially in this area should endeavor to adopt IoT in their research activities to investigate the efficacy of IoT in improving the business management and accounting field. Similarly, future bibliometric research should focus on detail analysis of IoT research by exploring all other sub-systems using more detailed manual reviews to summarize the existing researches in the area of IoT

\section{CONCLUSION}

This review comprehensively analysed 9,367 research-based articles on Internet of Thing part of the industry 4.0 in the past 10 years using bibliometric analysis procedure. Specifically, the source journals were quantitatively analyzed, and the most productive journals authors, countries and subject areas were revealed through co-authorship analysis, as well as their network distribution. The citation networks and 15 key articles were identified via citation analysis. More importantly, based on countries productivity, keyword co-occurrence and major subject/discipline areas of IoT application in research, a critical analysis of current challenges, gaps and future directions were ultimately discussed. Overall, this study revealed some interesting findings, can also help researchers to locate research hot spots and gaps by offering comprehensive analyses, and structured information on this topic.

\section{REFERENCES}

1. A. C. Pereira, F. Romero, A. C. Pereira, and F. Romero, "ScienceDirect ScienceDirect ScienceDirect ScienceDirect A review of the meanings and the implications of the Industry 4 . 0 review of the meanings and the implications of the Industry concept Costing models for capacity optimization in Industry 4.0: Trade-off between used capacity operational efficiency," Procedia Manuf., vol. 13, pp. 1206-1214, 2017.

2. R. M. Dijkman, B. Sprenkels, T. Peeters, and A. Janssen, "Business models for the Internet of Things," Int. J. Inf. Manage., vol. 35, no. 6 , pp. 672-678, 2015.

3. S. H. Bonilla, H. R. O. Silva, M. T. da Silva, R. F. Gonçalves, and J. B. Sacomano, "Industry 4.0 and sustainability implications: A scenario-based analysis of the impacts and challenges," Sustain., vol. 10 , no. 10,2018

4. A. A. Bergström and S. Venema, "Industry 4.0: An Opportunity or a Threat?: A Qualitative Study Among Manufacturing Companies," p. 104, 2018

5. T. Saarikko, U. H. Westergren, and T. Blomquist, "The Internet of Things: Are you ready for what's coming?," Bus. Horiz., vol. 60, no. 5, pp. 667-676, 2017.

6. M. D. Assunção, R. N. Calheiros, S. Bianchi, M. A. S. Netto, and R. Buyya, "Big Data computing and clouds: Trends and future directions," J. Parallel Distrib. Comput., vol. 79-80, pp. 3-15, 2015.

7. A. Rosell, "Towards a Framework for Identifying Digital Improvement Opportunities - Utilizing Information Flow and its Stakeholder Value,' 2018.

8. E. Sener and A. N. Yuksel, "The reflections of digitalization at organizational level: industry 4.0 in Turkey," Pressacademia, vol. 6, no. 3, pp. 291-300, 2017.

9. T. D. Oesterreich and F. Teuteberg, "Understanding the implications of digitisation and automation in the context of Industry 4.0: A triangulation approach and elements of a research agenda for the construction industry," Computers in Industry. 2016.

10. B. Tjahjono, C. Esplugues, E. Ares, and G. Pelaez, "What does Industry 4.0 mean to Supply Chain?," Procedia Manuf., vol. 13, pp. 1175-1182, 2017.

11. A. N. El-Kassar and S. K. Singh, "Green innovation and organizational performance: The influence of big data and the moderating role of management commitment and HR practices," Technol. Forecast. Soc. Change, vol. 144, no. November 2017, pp. 483-498, 2019.

12. W. S. Alaloul, M. S. Liew, N. A. W. A. Zawawi, and B. S. Mohammed, "Industry Revolution IR 4.0: Future Opportunities and Challenges in Construction Industry," MATEC Web Conf., vol. 203, p. 02010, 2018.

13. Z. Zakuri, "Wireless Smart Home Security System GSM Alarm," Mudah.my, 2019. [Online]. Available: https://www.mudah.my/Wireless+Smart+Home+Security+System+G SM+Alarm-61248693.htm\#btRy10UEYxmDoIRA.99. [Accessed: 13-Jul-2019].

14. P. Diodato, V. P., \& Gellatly, Dictionary of Bibliometrics. 2013.

15. A. Aghaei Chadegani et al., "A comparison between two main academic literature collections: Web of science and scopus databases," Asian Soc. Sci., vol. 9, no. 5, pp. 18-26, 2013.

16. E. S. Vieira and J. A. N. F. Gomes, "A comparison of Scopus and Web of science for a typical university," Scientometrics, vol. 81, no. 2, pp. 587-600, 2009.

17. N. J. van Eck and L. Waltman, "Text mining and visualization using VOSviewer," pp. 1-5, 2011.

18. S. M. Riazul Islam, Daehan Kwak, M. Humaun Kabir, M. Hossain, and Kyung-Sup Kwak, "The Internet of Things for Health Care: A Comprehensive Survey," IEEE Access, vol. 3, pp. 678-708, 2015.

19. A. Zanella, N. Bui, A. Castellani, L. Vangelista, and M. Zorzi, "Internet of things for smart cities," IEEE Internet Things J., vol. 1, no. 1, pp. 22-32, 2014.

20. A. Augustin, J. Yi, T. Clausen, and W. M. Townsley, "A study of Lora: Long range \& low power networks for the internet of things," Sensors (Switzerland), vol. 16, no. 9, pp. 1-18, 2016.

21. J. Gubbi, R. Buyya, S. Marusic, and M. Palaniswami, "Internet of Things (IoT): A vision, architectural elements, and future directions," Futur. Gener. Comput. Syst., vol. 29, no. 7, pp. 1645-1660, 2013.

22. S. Wang, J. Wan, D. Li, and C. Zhang, "Implementing Smart Factory of Industrie 4.0: An Outlook," Int. J. Distrib. Sens. Networks, vol. 2016, 2016. 
Trends in Industry 4.0 Research: A Bibliometric Analysis of Publications in Internet of Thing Component

23. S. Vashi, J. Ram, J. Modi, S. Verma, and C. Prakash, "Internet of Things (IoT): A vision, architectural elements, and security issues," Proc. Int. Conf. IoT Soc. Mobile, Anal. Cloud, I-SMAC 2017, no. December, pp. 492-496, 2017.

24. F. Tao, Y. Cheng, L. Da Xu, L. Zhang, and B. H. Li, "CCIoT-CMfg: Cloud computing and internet of things-based cloud manufacturing service system," IEEE Trans. Ind. Informatics, vol. 10, no. 2, pp. $1435-1442,2014$.

25. F. Ullah, M. A. Habib, M. Farhan, S. Khalid, M. Y. Durrani, and S. Jabbar, "Semantic interoperability for big-data in heterogeneous IoT infrastructure for healthcare," Sustain. Cities Soc., vol. 34, pp. 90-96, 2017.

26. S. Tomovic, K. Yoshigoe, I. Maljevic, and I. Radusinovic, "Software-Defined Fog Network Architecture for IoT," Wirel. Pers. Commun., vol. 92, no. 1, pp. 181-196, 2017.

27. J. A. Jiang et al., "A distributed rss-based localization using a dynamic circle expanding mechanism," IEEE Sens. J., vol. 13, no. 10, pp. 3754-3766, 2013.

28. K. Malarvizhi and R. Kiruba, "A novel method of supervision and control of first order level process using Internet of Things," J. Adv. Res. Dyn. Control Syst., vol. 9, no. Special Issue 6, pp. 1876-1894, 2017.

29. L. Atzori, A. Iera, and G. Morabito, "The Internet of Things: A survey," Comput. Networks, vol. 54, no. 15, pp. 2787-2805, 2010.

30. Z. Yan, P. Zhang, and A. V. Vasilakos, "A survey on trust management for Internet of Things,” J. Netw. Comput. Appl., vol. 42, pp. 120-134, 2014.

31. S. Jain, K. N. Vinoth, A. Paventhan, V. Kumar Chinnaiyan, V Arnachalam, and M. Pradish, "Survey on smart grid technologies-smart metering, IoT and EMS," 2014 IEEE Students Conf. Electr. Electron. Comput. Sci. SCEECS 2014, pp. 1-6, 2014. 